ARTICLE

Received 16 Sep 2013 | Accepted 15 Jan 2014 | Published 10 Feb $2014 \quad$ DOl: 10.1038/ncomms4264

\title{
Toward atomically-precise synthesis of supported bimetallic nanoparticles using atomic layer deposition
}

\author{
Junling Lu', Ke-Bin Low², Yu Lei ${ }^{3}$, Joseph A. Libera ${ }^{3}$, Alan Nicholls ${ }^{2}$, Peter C. Stair ${ }^{4,5} \&$ Jeffrey W. Elam ${ }^{3}$
}

Multi-metallic nanoparticles constitute a new class of materials offering the opportunity to tune the properties via the composition, atomic ordering and size. In particular, supported bimetallic nanoparticles have generated intense interest in catalysis and electrocatalysis. However, traditional synthesis methods often lack precise control, yielding a mixture of monometallic and bimetallic particles with various compositions. Here we report a general strategy for synthesizing supported bimetallic nanoparticles by atomic layer deposition, where monometallic nanoparticle formation is avoided by selectively growing the secondary metal on the primary metal nanoparticle but not on the support; meanwhile, the size, composition and structure of the bimetallic nanoparticles are precisely controlled by tailoring the precursor pulse sequence. Such exquisite control is clearly demonstrated through in situ Fourier transform infrared spectroscopy of $\mathrm{CO}$ chemisorption by mapping the gradual atomicscale evolution in the surface composition, and further confirmed using aberration-corrected scanning transmission electron microscopy.

\footnotetext{
${ }^{1}$ Department of Chemical Physics, University of Science and Technology of China, Hefei 230026, China. ${ }^{2}$ Research Resources Center, University of Illinois at Chicago, Chicago, Illinois 60607, USA. ${ }^{3}$ Energy Systems Division, Argonne National Laboratory, Argonne, Illinois 60439, USA. ${ }^{4}$ Chemical Sciences \& Engineering Division, Argonne National Laboratory, Argonne, Illinois 60439, USA. ${ }^{5}$ Department of Chemistry, Northwestern University, Evanston, Illinois 60208, USA. Correspondence and requests for materials should be addressed to J.W.E. (email: jelam@anl.gov).
} 
B imetallic nanoparticles often show unique electrical, magnetic, optical and catalytic properties that are distinct from those of their parent metals, making them a new class of materials with enhanced properties because of synergistic effects $^{1-7}$. These materials have gained broad interest for a range of applications. In particular, bimetallic nanoparticles supported on oxides (or carbon) have been used extensively in catalytic ${ }^{2,4,7-12}$ and electrocatalytic ${ }^{5,13-16}$ applications such as hydrocarbon reforming, water-gas-shift and fuel cells. Traditional methods for bimetallic nanoparticle synthesis such as successive impregnation or co-impregnation often fail to provide precise control over composition and structure, yielding a mixture of monometallic and bimetallic particles with various compositions ${ }^{2,7,17}$. This heterogeneity will obfuscate any effort to link properties to structural or compositional changes, and can significantly reduce the catalytic performance. Monnier et al. ${ }^{18}$ recently utilized electroless deposition to promote the selective growth of a second metal on the surface of a pre-existing metal without forming isolated clusters of the second metal on the catalyst support. However, the coverage of the second metal was limited to the submonolayer region, and the synthesis of well-mixed alloys using this approach might be challenging. Consequently, a more general method for bimetallic nanoparticle synthesis with atomically precise control is still missing.

Atomic layer deposition (ALD) is a variation of chemical vapour deposition, wherein thin films are grown via a sequence (usually binary) of self-limiting chemical reactions between precursor vapours and the surface ${ }^{19-21}$. The self-limiting character of the reactions makes it possible to achieve uniform deposits on high surface area or porous solids ${ }^{22-24}$. Hence, the design and synthesis of advanced nanoscale catalysts become possible through independent control over the structure and composition of the underlying support, the catalytically active sites and the protective overlayer ${ }^{25-27}$. ALD has proven successful for the controlled synthesis of supported monometallic catalysts ${ }^{24,26,28}$. Although there have been a few reports of bimetallic nanoparticles by ALD, these have been limited to the case where the two metals share a similar surface chemistry and deposition temperature 29,30 , and no strategy was provided for controlling the deposition of the secondary metal selectively on the primary metal nanoparticle but not on the support to exclude monometallic formation. Very recently, Kessels et al. ${ }^{31}$, reported the selective ALD of a $\mathrm{Pt}$ shell on Pd particles supported on planar substrates using a low oxygen pressure at $300^{\circ} \mathrm{C}$, where the $\mathrm{Pd}$ core was prepared at $100^{\circ} \mathrm{C}$ using a $\mathrm{H}_{2}$ plasma as the reducing agent. In addition, they reported the selective ALD of a Pd shell on Pt nanoparticles using $\mathrm{H}_{2}$ as the reductant at $100^{\circ} \mathrm{C}$, where the $\mathrm{Pt}$ core was prepared using a high oxygen pressure at $300^{\circ} \mathrm{C}$. However, the use of a plasma renders the method unsuitable for high surface area or high aspect ratio substrates where the radical species in the plasma would recombine before reaching the inner surfaces. Moreover, the need to perform the growth of the two metals at different temperatures is inconvenient, and makes the growth of bimetallic alloy nanoparticles, where the two ALD metal processes must be frequently alternated, practically impossible.

Here we report a general strategy for synthesizing supported bimetallic nanoparticles by ALD that overcomes these limitations. By properly selecting the deposition temperature and the appropriate co-reactant, we achieve selective deposition of the second metal only on the surfaces of the first metal without the need for a plasma, which is illustrated using in situ quartz crystal microbalance (QCM) measurements. Moreover, by maintaining a constant temperature for the multiple metal ALD processes, the synthesis of well-mixed alloy nanoparticles is accomplished. In situ Fourier transform infrared spectroscopy
(FTIR) of CO chemisorption clearly demonstrates the atomically precise control offered by ALD through mapping the atomic-scale evolution of the nanoparticle surface composition after every ALD cycle of the selectively deposited secondary metal, and from these measurements both the nanoparticle structure and the stability are inferred at elevated temperatures. Moreover, aberration-corrected scanning transmission electron microscopy (STEM), along with elemental line profile analysis, confirms the composition and structure of the bimetallic nanoparticles. Our results demonstrate a general methodology for the atomically precise, low temperature synthesis of supported bimetallic or multi-metallic nanoparticles on both planar and porous surfaces suitable for catalysis and other applications.

\section{Results}

Low temperature selective metal ALD. We first employed in situ QCM measurements to establish the appropriate conditions to accomplish the selective deposition of ALD metals on metal surfaces while avoiding growth on oxide surfaces. In these studies, a primary metal or oxide starting surface was first deposited onto the quartz crystal sensor by ALD, and then the initial growth behaviour of the secondary metal was recorded. A variety of deposition temperatures, co-reactants and pulse-sequencing strategies were explored to achieve the desired selectivity. Figure 1 summarizes the successful processes we discovered. On Pt or $\mathrm{Ru}$ metal surfaces, Pd ALD using Pd(II) hexafluoroacetylacetonate $\left(\mathrm{Pd}(\mathrm{hfac})_{2}\right)$ and $\mathrm{H}_{2}$ at $150^{\circ} \mathrm{C}$ exhibits linear growth without any nucleation delay (Fig. 1a). A slightly higher initial growth rate was obtained on $\mathrm{Pt}$ than on $\mathrm{Ru}$. In contrast, no $\mathrm{Pd}$ growth was observed under these conditions on $\mathrm{Al}_{2} \mathrm{O}_{3}, \mathrm{TiO}_{2}$ or $\mathrm{ZrO}_{2}$ surfaces except for the small mass uptake during the first $\mathrm{Pd}(\mathrm{hfac})_{2}$ exposure (also seen in Supplementary Fig. 1). Similarly, Pt ALD showed linear growth on Pd and nearly on Ru surfaces using trimethyl(methylcyclopentadienyl)-platinum(IV) $\left(\mathrm{MeCpPtMe}_{3}\right)$ and $\mathrm{O}_{2}$ at $150^{\circ} \mathrm{C}$ (Fig. 1b). The Pt ALD was slightly inhibited initially on the $\mathrm{Ru}$ surface. Again, negligible $\mathrm{Pt}$ growth was observed on the $\mathrm{Al}_{2} \mathrm{O}_{3}, \mathrm{TiO}_{2}$ and $\mathrm{ZrO}_{2}$ surfaces under the same conditions (also seen in Supplementary Figs 2 and 3$)^{32}$.

$\mathrm{Ru} \mathrm{ALD}$ has been accomplished previously using bis(ethylcyclopentadienyl)ruthenium $\left(\mathrm{Ru}(\mathrm{EtCp})_{2}\right)$ and $\mathrm{O}_{2}$ at $300^{\circ} \mathrm{C}$ (ref. 33), here we found that $\mathrm{Ru}$ ALD does not proceed below $200^{\circ} \mathrm{C}$ (Supplementary Fig. 4a). To achieve $\mathrm{Ru}$ ALD at $150^{\circ} \mathrm{C}$ where the $\mathrm{Pt}$ and $\mathrm{Pd} \mathrm{ALD}$ were selective, we adopted an $\mathrm{ABC}$-type strategy using the exposure sequence: $\mathrm{Ru}(\mathrm{EtCp})_{2}, \mathrm{O}_{2}$ and $\mathrm{H}_{2}$. In this process, the $\mathrm{Ru}(\mathrm{EtCp})_{2}$ should undergo dissociative chemisorption on the existing $\mathrm{Ru}$ surface, the $\mathrm{O}_{2}$ is expected to burn off the EtCp ligand forming $\mathrm{Ru}$ oxide, and the $\mathrm{H}_{2}$ should reduce the $\mathrm{Ru}$ oxide to $\mathrm{Ru}$ metal. In agreement with this expected mechanism, the ABC sequence yielded Ru ALD at much lower temperatures and provided $\sim 0.21 \AA$ per cycle $\left(22.4 \mathrm{ng} \mathrm{cm}^{-2}\right.$ per cycle) at $200^{\circ} \mathrm{C}$ and $0.1 \AA$ per cycle $\left(10.5 \mathrm{ng} \mathrm{cm}^{-2}\right.$ per cycle) at $150^{\circ} \mathrm{C}$ (Supplementary Fig. $4 \mathrm{~b}$ ). Moreover, the ABC Ru ALD enabled selective growth on $\mathrm{Pd}$ or $\mathrm{Pt}$ surfaces but not on $\mathrm{Al}_{2} \mathrm{O}_{3}, \mathrm{TiO}_{2}$ and $\mathrm{ZrO}_{2}$ surfaces at $200^{\circ} \mathrm{C}$ (Fig. 1c). The higher initial $\mathrm{Ru}$ growth rates observed on the $\mathrm{Pd}$ and Pt surfaces at $150{ }^{\circ} \mathrm{C}$ suggest that these metals facilitate the $\mathrm{Ru}$ nucleation and growth.

Figure 1 demonstrates the selective ALD of secondary metals on primary metal surfaces, but of course a compatible ALD process is also required to deposit the primary metal on the oxide support to initiate the bimetallic growth. Fortunately, Pd ALD can be accomplished on oxide surfaces at $150^{\circ} \mathrm{C}$ using $\mathrm{HCHO}$ as the coreactant (Supplementary Fig. 1) 28,34 . Similarly, Pt ALD can be achieved on oxide surfaces at the low temperatures needed for selective growth of the secondary metal using $\mathrm{O}_{3}$ as the coreactant (Supplementary Fig. 3). This strategy, when coupled with the 

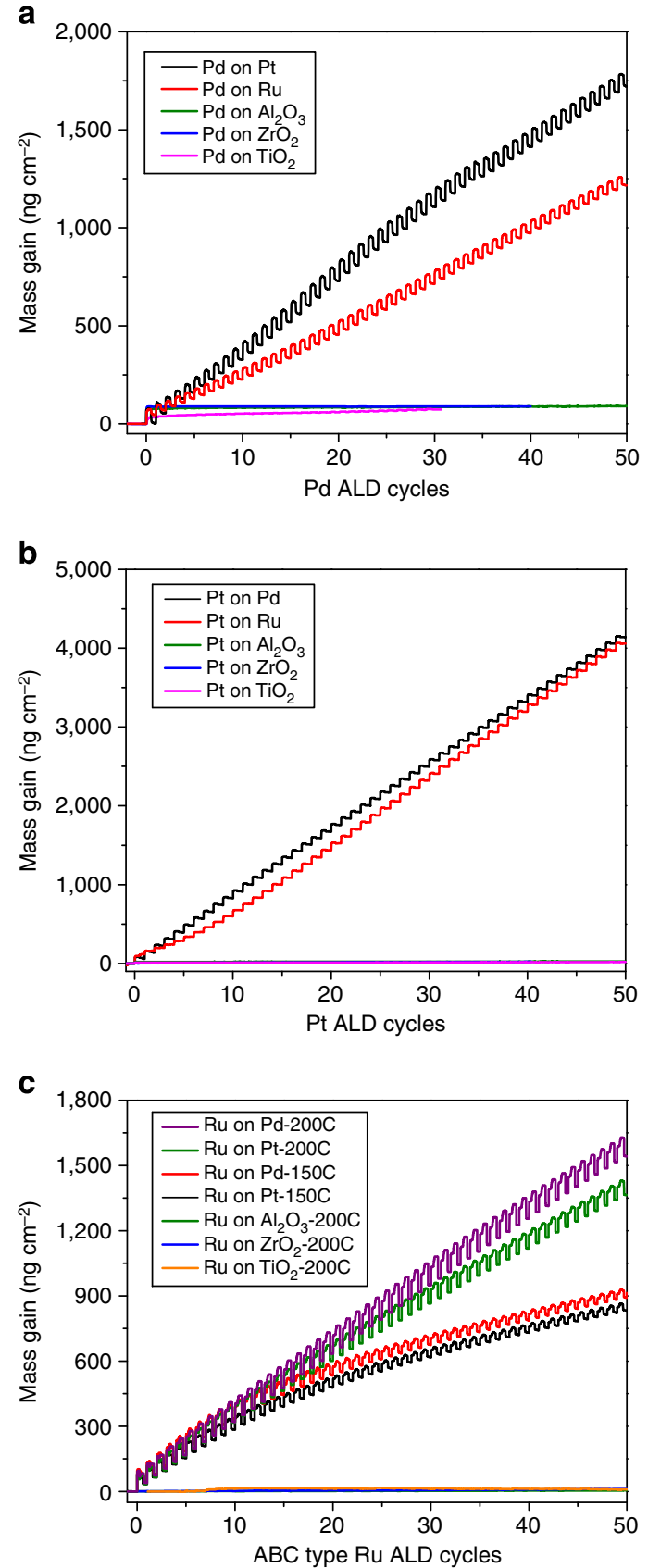

Figure 1 | In situ QCM measurements of ALD on metal and oxide surfaces. (a) $\mathrm{Pd} A L D$ on $\mathrm{Pt}, \mathrm{Ru}, \mathrm{Al}_{2} \mathrm{O}_{3}, \mathrm{TiO}_{2}$ and $\mathrm{ZrO}_{2}$ using $\mathrm{Pd}(\mathrm{hfac})_{2}$ and $\mathrm{H}_{2}$ at $150^{\circ} \mathrm{C}$. (b) Pt $\mathrm{ALD}$ on $\mathrm{Pd}, \mathrm{Ru}_{1} \mathrm{Al}_{2} \mathrm{O}_{3}, \mathrm{TiO}_{2}$ and $\mathrm{ZrO}_{2}$ using $\mathrm{MeCpPtMe}_{3}$ and $\mathrm{O}_{2}$ at $150^{\circ} \mathrm{C}$. (c) ABC-type Ru ALD on Pd and Pt at 150 and $200^{\circ} \mathrm{C}$, and on $\mathrm{Al}_{2} \mathrm{O}_{3}, \mathrm{TiO}_{2}$ and $\mathrm{ZrO}_{2}$ at $200^{\circ} \mathrm{C}$ using $\mathrm{Ru}(\mathrm{EtCp})_{2}$, $\mathrm{O}_{2}$ and $\mathrm{H}_{2}$

saturating reactions of the secondary metal on the primary metal surface leads exclusively to bimetal nanoparticles without forming monometallic nanoparticles of the primary or the secondary metal.

Using the methods described above, bimetallic core-shell nanoparticles can in principle be formed on oxide surfaces with precise control over the shell thickness by adjusting the number of ALD cycles for the secondary metal. The ALD of well-mixed bimetallic alloy nanoparticles could also be accomplished by alternating between the ALD processes for the individual metals, but certain requirements must be satisfied. Besides the requirement of the selective deposition of each metal component, the surface chemistries for the two components must be mutually compatible and ALD of two metals should proceed at the same temperature for practicality. Figure 2 shows in situ QCM measurements of well-mixed metal alloy ALD for all possible combinations: PdPt, RuPd and RuPt. The PdPt, RuPd and RuPt alloy ALD yield linear growth at $150^{\circ} \mathrm{C}$ as shown in Fig. 2a. The PdPt well-mixed alloy was accomplished using the sequence: $\mathrm{MeCpPtMe}_{3}-\mathrm{O}_{2}-\mathrm{H}_{2}-\mathrm{Pd}(\mathrm{hfac})_{2}-\mathrm{H}_{2}-\mathrm{O}_{2}$ (ABC-type $\mathrm{Pt}$ with ABCtype $\mathrm{Pd}$ ALD). The $\mathrm{H}_{2}$ exposure after the $\mathrm{O}_{2}$ exposure in each $\mathrm{Pt}$ ALD cycle reduces the surface and enhances the Pd growth. In the absence of the extra $\mathrm{H}_{2}$ exposure, the Pd ALD is suppressed (Supplementary Fig. 5). This is probably due to $\mathrm{Pd}(\mathrm{hfac})_{2}$ dissociation by the chemisorbed oxygen. Similarly, an $\mathrm{O}_{2}$ exposure added after the $\mathrm{H}_{2}$ exposure in each Pd ALD cycle oxidizes the surface to facilitate the subsequent $\mathrm{MeCpPtMe}_{3}$ adsorption for the Pt ALD. 1c-Pt ALD followed by 1c-Pd ALD yielded a $\mathrm{Pd}: \mathrm{Pt}$ mole ratio of about 1:1 (Fig. 2b). Combining ABC-type Pt with AB-type Pd ALD barely changed the overall growth rate for the alloy, but changed the mole ratio to $\mathrm{Pd}: \mathrm{Pt}=4: 3$ (Supplementary Fig. 6). Well-mixed RuPd alloy growth was achieved using the ALD sequence: $\mathrm{Ru}(\mathrm{EtCp})_{2}-\mathrm{O}_{2}$ $\mathrm{H}_{2}-\mathrm{Pd}(\mathrm{hfac})_{2}-\mathrm{H}_{2}$ at $150^{\circ} \mathrm{C}$, which gave a $\mathrm{Ru}: \mathrm{Pd}$ mole ratio of about 3:5 (Fig. 2c). Similarly, a well-mixed RuPt alloy was accomplished using the sequence: $\mathrm{Ru}(\mathrm{EtCp})_{2}-\mathrm{O}_{2}-\mathrm{H}_{2}$ $\mathrm{MeCpPtMe}_{3}-\mathrm{O}_{2}-\mathrm{H}_{2}$ at $150{ }^{\circ} \mathrm{C}$, which yielded a Ru:Pt mole ratio of $1: 1$ (Fig. 2d). It is notable that the ABC-type Ru ALD showed a higher growth per cycle during the RuPt alloy ALD $\left(30.6 \mathrm{ng} \mathrm{cm}^{-2}\right.$, Fig. 2d), than on itself $\left(10.5 \mathrm{ng} \mathrm{cm}^{-2}\right.$, Supplementary Fig. 4). Similar behaviour is also seen in Fig. 1c, where the Ru growth per cycle is higher initially on the Pt surface, but then declines to a lower value following $\sim 15$ cycles where the surface has converted to $\mathrm{Ru}$.

In situ CO chemisorption FTIR during ALD synthesis. The QCM results in Figs 1 and 2 demonstrate that the atomically precise synthesis of supported bimetallic nanoparticles should be possible, wherein the composition, structure and size of the nanoparticles can be controlled by adjusting the ALD pulse sequence ${ }^{27}$. To validate this approach, we employed FTIR to interrogate the surface of the bimetallic nanoparticles after each ALD cycle of the secondary metal. FTIR of CO chemisorption has been widely used to characterize the surface composition of bimetallic nanoparticles ${ }^{4,35-38}$. By performing in situ FTIR measurements of $\mathrm{CO}$ chemisorption after each ALD cycle during the bimetallic nanoparticle synthesis, we can map the atomic-scale evolution of the surface composition and thereby infer the nanoparticle structure (for example, core-shell versus well-mixed alloy). Figure 3 a illustrates the growth of a Pt shell on an $\mathrm{ALD} \mathrm{Pd} / \mathrm{Al}_{2} \mathrm{O}_{3}$ sample (Supplementary Fig. 7), which was prepared using four ALD Pd cycles at $200^{\circ} \mathrm{C}$. The FTIR spectrum for $\mathrm{CO}$ adsorbed on the bare $\mathrm{Pd} / \mathrm{Al}_{2} \mathrm{O}_{3}$ sample (Fig. 3a, 0c-Pt) showed a weak peak at $2,067 \mathrm{~cm}^{-1}$ and a strong peak at $1,917 \mathrm{~cm}^{-1}$ with a broad shoulder at around $1,850 \mathrm{~cm}^{-1}$, which we assign to linear $\mathrm{CO}$ on steps/corners of the Pd nanoparticles and bridge/threefold-hollow $\mathrm{CO}$ on the $\operatorname{Pd}(111)$ facets, respectively ${ }^{25,39}$. After one Pt ALD cycle, the IR spectrum (1c$\mathrm{Pt}$ ) revealed that the linear $\mathrm{CO}$ intensity increased remarkably along with a red shift to $2,054 \mathrm{~cm}^{-1}$, attributable to linear $\mathrm{CO}$ on $\mathrm{Pt}^{40}$; meanwhile, the dominant peak at $1,917 \mathrm{~cm}^{-1}$ decreased and shifted to $1,913 \mathrm{~cm}^{-1}$ indicating a reduction in the concentration of surface Pd. With increasing Pt ALD cycles this trend continued: the intensity of the linear $\mathrm{CO}$ feature increased substantially but shifted to the blue while the bridging CO feature decreased in intensity and shifted to the red. After $\sim 10$ Pt ALD 
a

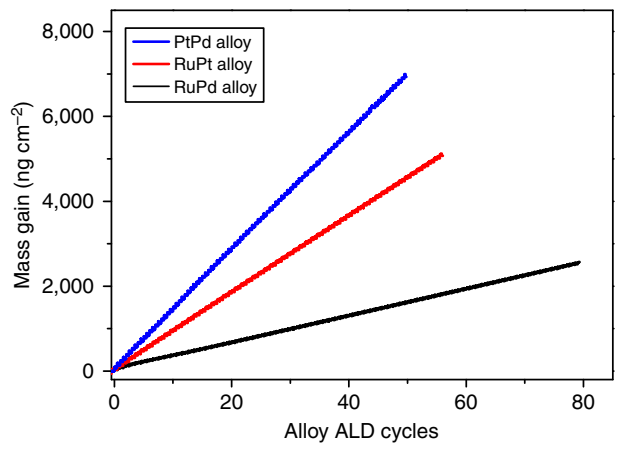

C

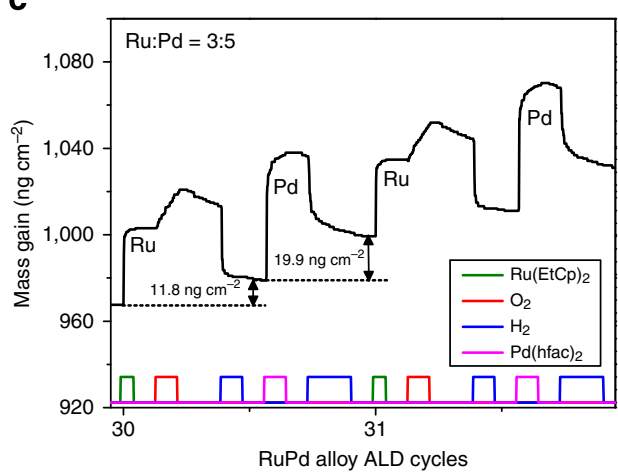

b

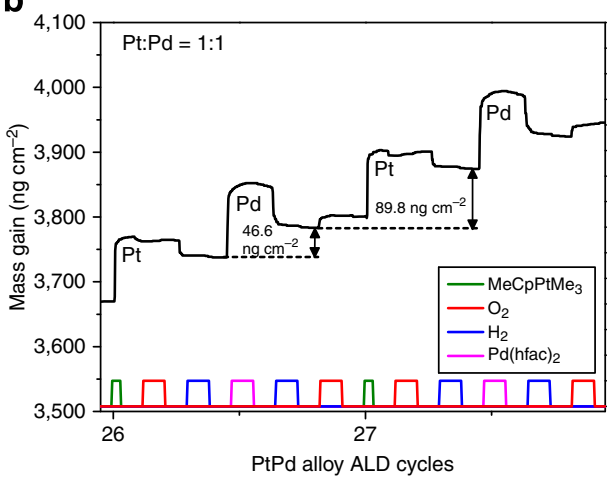

d

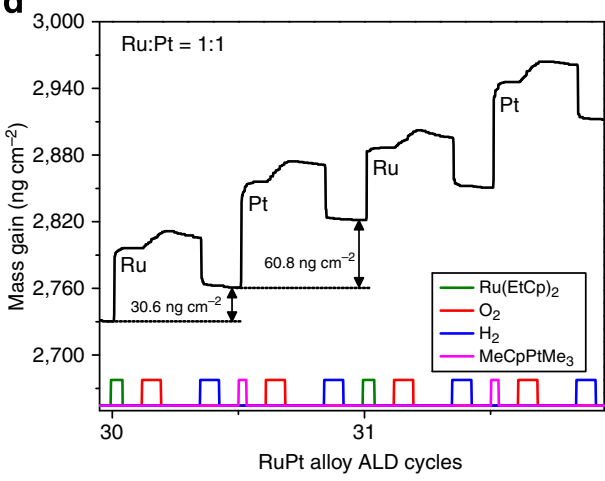

Figure 2 I In situ QCM studies of low temperature metal alloy ALD. (a) Linear growth of PtPd, RuPd and RuPt alloys by alternating between the ALD processes for the two metals. (b) Detailed mass changes during two PtPd alloy supercycles. (c) Detailed mass changes during two RuPd alloy supercycles. (d) Detailed mass changes during two RuPt alloy supercycles. The sequential exposure steps of each reactant are shown as columns in color at the bottom of each figure, nitrogen purge step is in between the columns.

cycles, the bridge-bonded $\mathrm{CO}$ peak at $1,917 \mathrm{~cm}^{-1}$ on $\mathrm{Pd}$ disappeared, leaving only a weaker peak at $1,851 \mathrm{~cm}^{-1}$, assigned to bridge-bonded $\mathrm{CO}$ on $\mathrm{Pt}^{40}$. This signals the completion of a continuous $\mathrm{Pt}$ shell on the $\mathrm{Pd}$ nanoparticle core. From Fig. 1b, the Pt mass added after 10 Pt ALD cycles corresponds to $\sim 1.5$ atomic monolayers $(\mathrm{ML})$.

Figure $3 \mathrm{~b}$ shows the complementary in situ CO chemisorption FTIR studies for $\mathrm{Pd} \mathrm{ALD}\left(\mathrm{Pd}(\mathrm{hfac})_{2}\right.$ and $\left.\mathrm{H}_{2}\right)$ on a $\mathrm{Pt} / \mathrm{Al}_{2} \mathrm{O}_{3}$ sample prepared using $1 \mathrm{c} \mathrm{Pt} \mathrm{ALD} \mathrm{at} 300^{\circ} \mathrm{C}$. Before the Pd ALD, two dominant linear CO peaks at 2,079 and $2,063 \mathrm{~cm}^{-1}$ along with a broad shoulder at $\sim 2,010 \mathrm{~cm}^{-1}$ were observed, which we assign to linear $\mathrm{CO}$ adsorbed on larger and smaller $\mathrm{Pt}$ nanoparticles, and low coordinated $\mathrm{Pt}$ atoms, respectively ${ }^{40}$; a very weak bridge-bonded $\mathrm{CO}$ peak at $\sim 1,851 \mathrm{~cm}^{-1}$ was seen, consistent with the literature. After one Pd ALD cycle, the IR spectrum (1c-Pd) revealed that the broad shoulder at $2,010 \mathrm{~cm}^{-1}$ disappeared, suggesting that Pd preferentially nucleated at the low coordination $\mathrm{Pt}$ surface sites. This finding is in excellent agreement with a recent theoretical study by Fortunelli et al. ${ }^{41}$ in which Pd mainly decorated the steps and corners of the Pt shell in multi-shell PdPt alloy nanoparticles. Meanwhile, a new peak appeared at $1,900 \mathrm{~cm}^{-1}$, which we assign to bridge-bonded CO on the PdPt mixture ${ }^{37}$. With increasing Pd ALD cycles, the linear $\mathrm{CO}$ on Pt continuously decreased in intensity and shifted to lower wavenumbers, implying that the number of surface $\mathrm{Pt}$ atoms diminished. Surprisingly, the $1,900 \mathrm{~cm}^{-1}$ peak remained and the characteristic bridge CO peak at $1,931 \mathrm{~cm}^{-1}$ for pure Pd surfaces was not observed even after $30 \mathrm{Pd}$ cycles $(\sim 3.5 \mathrm{ML} \mathrm{Pd})$. This finding suggests that $\mathrm{Pt}$ atoms diffuse to the surface during $\mathrm{Pd}$ ALD on the Pt core, to produce a Pd-rich PdPt shell.

Next, the PdPt well-mixed alloy ALD was investigated through in situ $\mathrm{CO}$ chemisorption FTIR at $150^{\circ} \mathrm{C}$ (Fig. 3c). First, a high density of Pt nanoparticles with less than $1 \mathrm{~nm}$ size were prepared on an alumina support using $12 \mathrm{Pt}$ ALD cycles $\left(\mathrm{MeCpPtMe}_{3}\right.$ and $\mathrm{O}_{3}$, Supplementary Fig. 8). Next, 'supercycles' of the PdPt alloy ALD were performed comprising $3 \mathrm{c}-\mathrm{Pd}$ ALD followed by $2 \mathrm{c}-\mathrm{Pt}$ $\mathrm{ALD}$, and CO chemisorption was performed after each $3 \mathrm{c}-\mathrm{Pd}$ and $2 \mathrm{c}$-Pt step to probe the surface composition. Figure $3 \mathrm{c}$ illustrates $\mathrm{CO}$ chemisorption spectra following the 4th, 5th and 6th supercycles. Following each of the 3c-Pd step, the linear CO peak on $\mathrm{Pt}$ is suppressed while the $1,931 \mathrm{~cm}^{-1}$ peak (bridge CO on $\mathrm{Pd}$ ) increases, clearly demonstrating that Pd has covered a fraction of the surface $\mathrm{Pt}$ atoms. Similarly, each execution of the $2 c$-Pt step reversed these trends, indicating that Pt has covered some of the surface Pd atoms. These reversible changes in the spectral features persisted over multiple supercycles (Fig. $3 \mathrm{c}$ and Supplementary Fig. 9), providing solid evidence for the formation of a well-mixed PdPt alloy.

Figure 3d illustrates in situ CO chemisorption FTIR studies of $\mathrm{Ru} \mathrm{ALD}$ on a $\mathrm{Pt} / \mathrm{Al}_{2} \mathrm{O}_{3}$ sample at $200^{\circ} \mathrm{C}$. A gradual increase in the $\mathrm{Ru}$ surface coverage was observed with increasing $\mathrm{Ru}$ ALD cycles as evidenced by the decease of linear $\mathrm{CO}$ on $\mathrm{Pt}$ and the appearance of a new peak at $2,010 \mathrm{~cm}^{-1}$, which we assign to linear $\mathrm{CO}$ on $\mathrm{Ru}^{38}$. Similar to the observations in Fig.3b, Pt CO features persisted even after $35 \mathrm{Ru}$ ALD cycles ( $\sim 3 \mathrm{Ru} \mathrm{ML})$, suggesting diffusion of $\mathrm{Pt}$ to the surface during the Ru ALD.

Structures of the ALD bimetallic nanoparticles. To further investigate the structures of the bimetallic nanoparticles, we utilized high-angle annular dark field (HAADF) aberrationcorrected STEM. Figure 4a shows the Pd-core Pt-shell nanoparticles prepared on spherical alumina using $5 \mathrm{c}$ Pd ALD $\left(\mathrm{Pd}(\mathrm{hfac})_{2}+\mathrm{HCHO}\right)$ followed by $15 \mathrm{c}$ Pt ALD $\left(\mathrm{MeCpPtMe}_{3}+\right.$ 

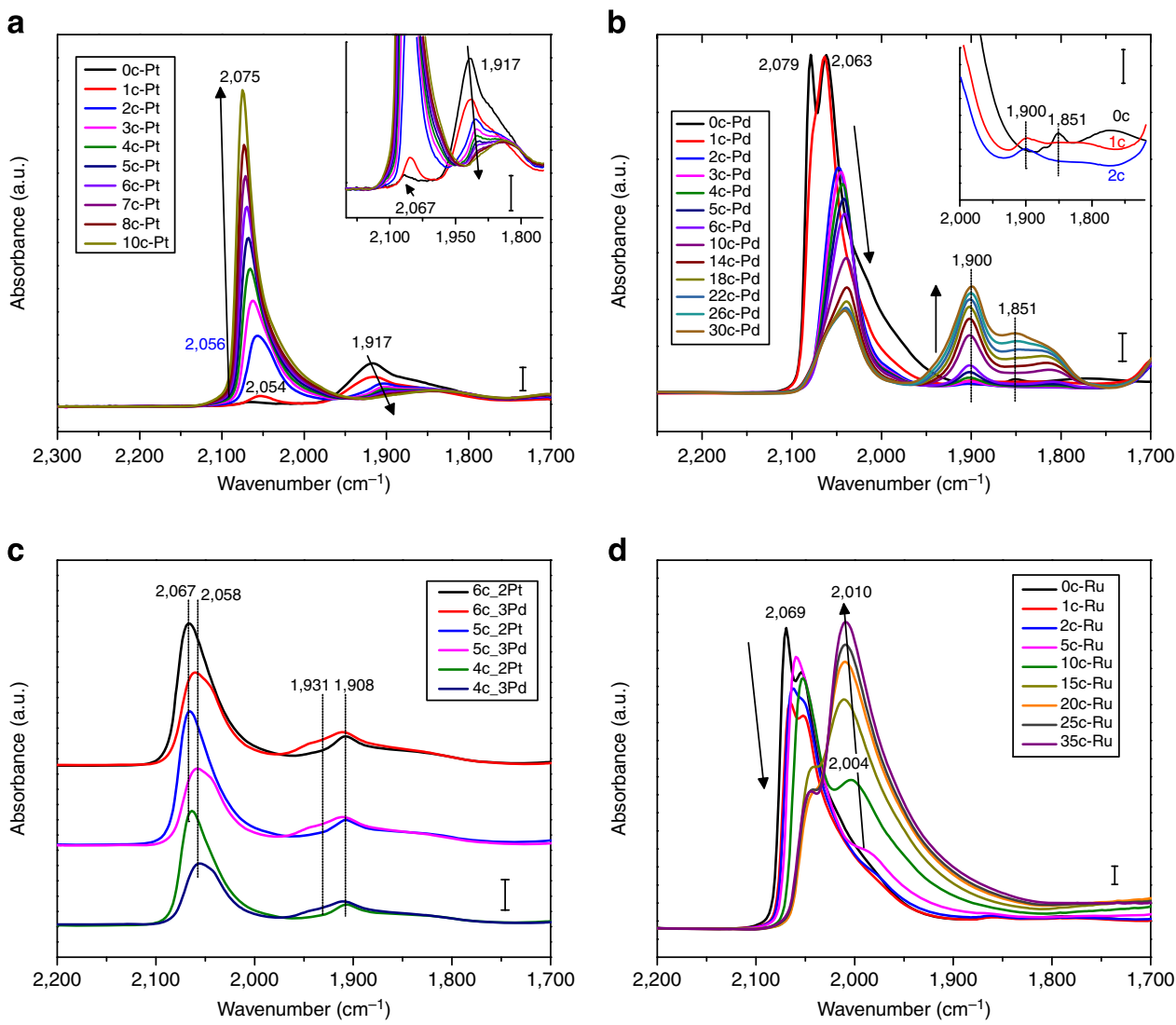

Figure 3 | In situ CO chemisorption FTIR measurements during ALD process. (a) ALD of Pt shell on an ALD Pd/Al $\mathrm{O}_{3}$ sample at $150{ }^{\circ} \mathrm{C}$. Scale bar, $1 \%$, scale bar for the inset, $0.5 \%$. (b) ALD of Pd shell on an ALD Pt/ $\mathrm{Al}_{2} \mathrm{O}_{3}$ sample at $150^{\circ} \mathrm{C}$. Scale bar, $3 \%$, scale bar for the inset, $1 \%$. (c) PtPd alloy ALD on an $\mathrm{ALD} \mathrm{Pt} / \mathrm{Al}_{2} \mathrm{O}_{3}$ sample at $150{ }^{\circ} \mathrm{C}$. Scale bar, $10 \%$. (d) ALD of Ru shell on an ALD Pt $/ \mathrm{Al}_{2} \mathrm{O}_{3}$ sample at $200^{\circ} \mathrm{C}$. Scale bar, $2 \%$.

$\mathrm{O}_{2}$ ) at $150^{\circ} \mathrm{C}$ that we designate: $5 \mathrm{Pd}$-core $15 \mathrm{Pt}$-shell (also seen in Supplementary Fig. 10). The 5Pd-core $15 \mathrm{cPt}$-shell nanoparticles were mono-dispersed with a particle size of $2.7 \pm 0.63 \mathrm{~nm}$. The STEM image with a higher magnification clearly demonstrated a Pd-core Pt-shell structure, where darker contrast is due to the atomically-lighter Pd and brighter contrast is attributed to the heavier Pt. The core-shell structure is further confirmed by the line profile analysis using STEM energy-dispersive spectroscopy (EDS). This observation is consistent with the in situ CO chemisorption FTIR studies.

Similarly, a sample of Pt-core Pd-shell bimetallic nanoparticles was prepared on spherical alumina using $12 \mathrm{c}$ Pt ALD $\left(\mathrm{MeCpPtMe}_{3}+\mathrm{O}_{3}\right)$ followed by 20c Pd ALD ( $\left.\mathrm{Pd}(\mathrm{hfac})_{2}+\mathrm{H}_{2}\right)$ at $150^{\circ} \mathrm{C}$ (12Pt-core 20Pd-rich-shell). Well-dispersed PtPd bimetallic nanoparticles were formed with a particle size of $2.5 \pm 0.51 \mathrm{~nm}$ (Fig. $4 \mathrm{~b}$ and Supplementary Fig. 11). Highresolution STEM imaging along with EDS line profile analysis suggests a Pd-rich PdPt shell-Pt core structure, in agreement with the weak Pt features observed during the in situ CO chemisorption FTIR measurements even after 30c Pd ALD.

Next, a well-mixed PtPd alloy sample was prepared on spherical alumina using 2c Pt ALD $\left(\mathrm{MeCpPtMe}_{3}+\mathrm{O}_{3}\right)$ at $150{ }^{\circ} \mathrm{C}$ to form subnanometer $\mathrm{Pt}$ nanoparticles as nucleation seeds, followed by ten PtPd alloy supercycles each comprised of 1c ABC Pd ALD ( $\mathrm{Pd}(\mathrm{hfac})_{2}+\mathrm{H}_{2}+\mathrm{O}_{2}$ ) and 1c ABC Pt ALD $\left(\mathrm{MeCpPtMe}_{3}+\mathrm{O}_{2}+\mathrm{H}_{2}\right)$. This sample is denoted as $12 \mathrm{Pt} 10 \mathrm{Pd}$ alloy. In Fig. 4c, the STEM image shows well-dispersed nanoparticles with a size of $2.5 \pm 0.43 \mathrm{~nm}$, and high resolution HAADF-STEM showed uniform contrast within each particle, indicating even mixing of Pt and Pd (also seen in Supplementary Fig. 12). Elemental line profile analysis provides further confirmation for the well-mixed PtPd alloy structure. Again, these findings corroborate the FTIR observations and illustrate the utility of the in situ FTIR technique for elucidating the bimetallic nanoparticle structure.

The same Pt-core Ru-shell sample grown during the in situ FTIR CO chemisorption studies (Fig. 3d) was examined by STEM. As shown in Fig. 4d and Supplementary Fig. 13, welldispersed PtRu bimetallic nanoparticles were formed with a particle size of $1.9 \pm 0.37 \mathrm{~nm}$, and the EDS line profile confirmed the presence of $\mathrm{Pt}$ atoms on the surface observed during the in situ CO chemisorption FTIR measurements.

Thermal stability of the ALD bimetallic nanoparticles. For practical purposes, it is important that the structure of the bimetallic nanoparticles should remain intact under catalytically relevant conditions. Here we briefly investigated the thermal stability of the bimetallic nanoparticles using in situ FTIR of CO chemisorption (Fig. 5). We found that the well-mixed 12Pt10Pd alloy nanoparticles were stable at temperatures below $300{ }^{\circ} \mathrm{C}$ in $\mathrm{N}_{2}, 10 \% \mathrm{O}_{2}$ or $10 \% \mathrm{H}_{2}$ indicated by the minor changes to the $\mathrm{CO}$ chemisorption features. While the linear $\mathrm{CO}$ on Pt surface (at $2,065 \mathrm{~cm}^{-1}$ ) decreased along with a considerable increase of the bridge $\mathrm{CO}$ on $\mathrm{Pd}\left(1,931 \mathrm{~cm}^{-1}\right)$ after flowing $10 \% \mathrm{H}_{2}$ at $400{ }^{\circ} \mathrm{C}$ for $1 \mathrm{~h}$ (Fig. 5a), suggesting the migration of $\mathrm{Pd}$ atoms onto the alloy surface. Similarly, the $1 \mathrm{Pt}$-core $35 \mathrm{Ru}$-rich-shell nanoparticles were also found to be rather stable below $300^{\circ} \mathrm{C}$ in both $10 \% \mathrm{O}_{2}$ and $10 \% \mathrm{H}_{2}$. While above this temperature, Pt atoms started migrating to the particle surface, especially in flowing $10 \%$ $\mathrm{H}_{2}$, indicated by the considerable growth of linear $\mathrm{CO}$ on $\mathrm{Pt}$ at $2,048 \mathrm{~cm}^{-1}$. 
a
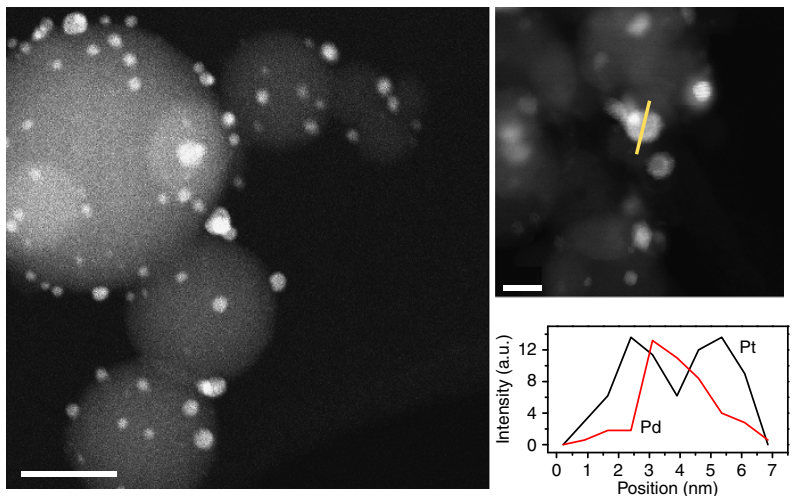

C
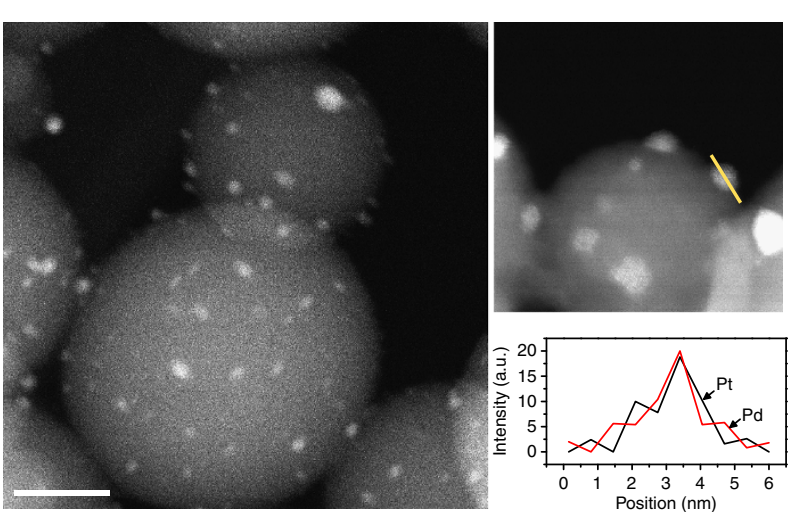

b
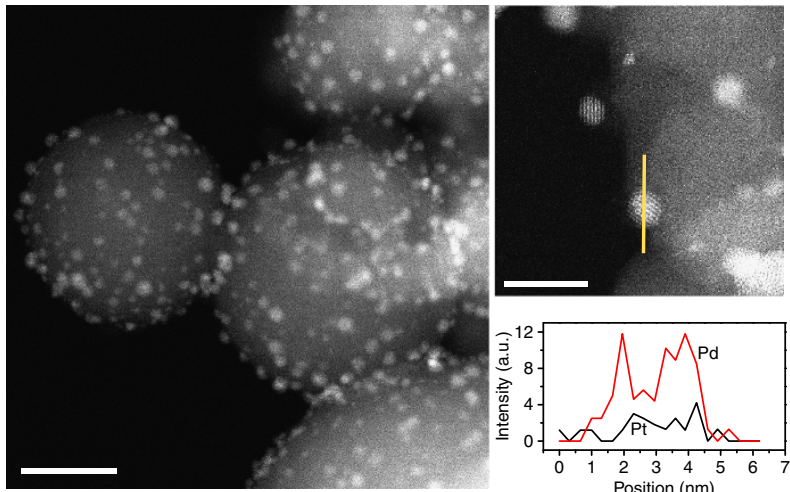

d

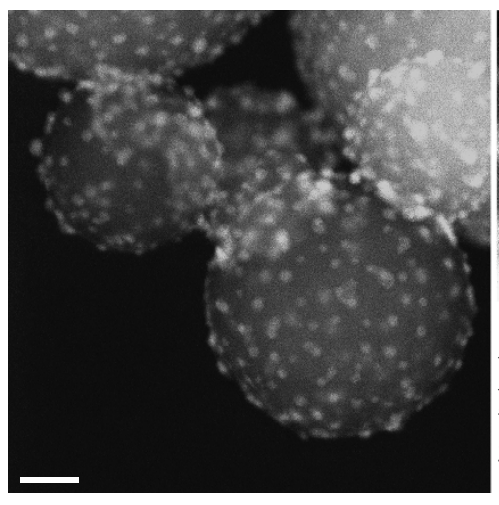

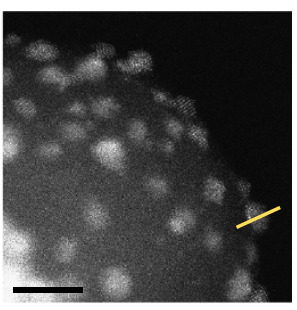

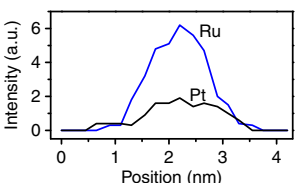

Figure 4 | Structures of ALD bimetallic nanoparticles. Representative aberration-corrected HAADF-STEM images and corresponding EDS line profiles of (a) 5Pd-core 15Pt-shell, (b) 12Pt-core 20Pd-rich-shell, (c) 12Pt10Pd alloy and (d) 1Pt-core 35Ru-rich-shell bimetallic nanoparticles on spherical alumina support.

\section{Discussion}

Challenges of supported bimetallic nanoparticle synthesis by ALD are that the deposition temperature and surface chemistry for the two metals are often different, and this complicates the task of combining them ${ }^{27}$. More importantly, no general strategy has emerged for achieving the selective growth of the secondary metal only on the primary metal surface while avoiding growth on the support to exclude monometallic nanoparticle formation.

Using in situ QCM measurements, we demonstrated that selective deposition can be achieved by judiciously selecting the co-reactant and deposition temperature. For example, choosing $\mathrm{H}_{2}$ instead of $\mathrm{HCHO}$ as the co-reactant for Pd ALD effectively suppresses Pd growth on oxide supports, while maintaining Pd growth on metal surfaces at $150{ }^{\circ} \mathrm{C}$ (Supplementary Fig. 1). This selectivity might be further improved by treating the oxide surface with an alkyl alcohol before the $\mathrm{Pd}(\mathrm{hfac})_{2}$ exposure to deactivate the oxide surface hydroxyl groups ${ }^{34,42}$. Reducing the deposition temperature is extremely effective at promoting selective ALD of the secondary metal. For instance, Pt ALD on $\mathrm{TiO}_{2}, \mathrm{Al}_{2} \mathrm{O}_{3}$, and $\mathrm{ZrO}_{2}$ surfaces can be greatly suppressed by lowering the temperature from 300 to $150^{\circ} \mathrm{C}$ (Supplementary Figs 2 and 3). In contrast, $\mathrm{Pt} \mathrm{ALD}$ at $150^{\circ} \mathrm{C}$ on $\mathrm{Pd}$ and Ru surfaces is essentially identical to the growth at $300^{\circ} \mathrm{C}$ (Fig. 1b). These contrasting behaviours for metal ALD on oxide versus metal surfaces facilitate the selective deposition at lower temperatures.

In addition to the selectivity requirement discussed above that applies to the ALD of all bimetallic nanoparticles, the synthesis of well-mixed alloy nanoparticles mandates that the surface chemistries for the two components should be mutually compatible ${ }^{29,43}$. For instance, Pd ALD is a hydrogenation reaction process where surface $\mathrm{H}^{*}$ are the active sites ${ }^{4,45}$; while
Pt ALD is a combustion reaction process, where surface $\mathrm{O}^{*}$ are the active sites ${ }^{46,47}$. The direct combination of AB type Pd ALD $\left(\mathrm{Pd}(\mathrm{hfac})_{2}+\mathrm{H}_{2}\right)$ with $\mathrm{AB}$ type $\mathrm{Pt} \mathrm{ALD}\left(\mathrm{MeCpPtMe}_{2}+\mathrm{O}_{2}\right)$ causes decomposition of the hfac ligands on the O-terminated surface, which can produce carbon and fluorine contamination and also suppress the Pd growth (Supplementary Fig. 5). In contrast, an $\mathrm{O}_{2}$ exposure added after the $\mathrm{H}_{2}$ exposure in each $\mathrm{Pd}$ ALD cycle can oxidize and O-terminate the surface in preparation for the subsequent $\mathrm{MeCpPtMe}_{3}$ adsorption in the next $\mathrm{Pt}$ cycle. Similarly, a $\mathrm{H}_{2}$ exposure added after the $\mathrm{O}_{2}$ exposure in each Pt ALD cycle can reduce and $\mathrm{H}$-terminate the surface for the subsequent $\mathrm{Pd}(\mathrm{hfac})_{2}$ adsorption in the next $\mathrm{Pd}$ ALD cycle. Implementing this ABC strategy can satisfy the surface chemistries of each ALD process and facilitate the growth of the two components (Supplementary Fig. 5). The higher growth rate observed for the alloy using this $\mathrm{ABC}$ method is beneficial for preparing supported $\mathrm{PdPt}$ alloy nanoparticles, because it further enhances the selective growth on the metal particle surface compared with the oxide support. We expect similar benefits from utilizing a $\mathrm{Ru}(\mathrm{EtCp})_{2}-\mathrm{O}_{2}-\mathrm{H}_{2}-\mathrm{Pd}(\mathrm{hfac})_{2}-\mathrm{H}_{2}$ sequence for $\mathrm{RuPd}$ alloy ALD and a $\mathrm{Ru}(\mathrm{EtCp})_{2}-\mathrm{O}_{2}-\mathrm{H}_{2}-$ $\mathrm{MeCpPtMe}_{3}-\mathrm{O}_{2}-\mathrm{H}_{2}$ sequence for RuPt ALD.

The selective growth of ALD metals on metal surfaces compared with oxide surfaces, coupled with the unique, selflimiting character of ALD allows atomically precise synthesis of supported bimetallic nanoparticles, a long-standing goal in catalyst synthesis. By tailoring the ALD pulse sequence, we can independently control the nanoparticle size, composition and structure. The size of the bimetallic particles is determined by the total number of ALD cycles performed. The composition is dictated by the relative number of ALD cycles used for each 

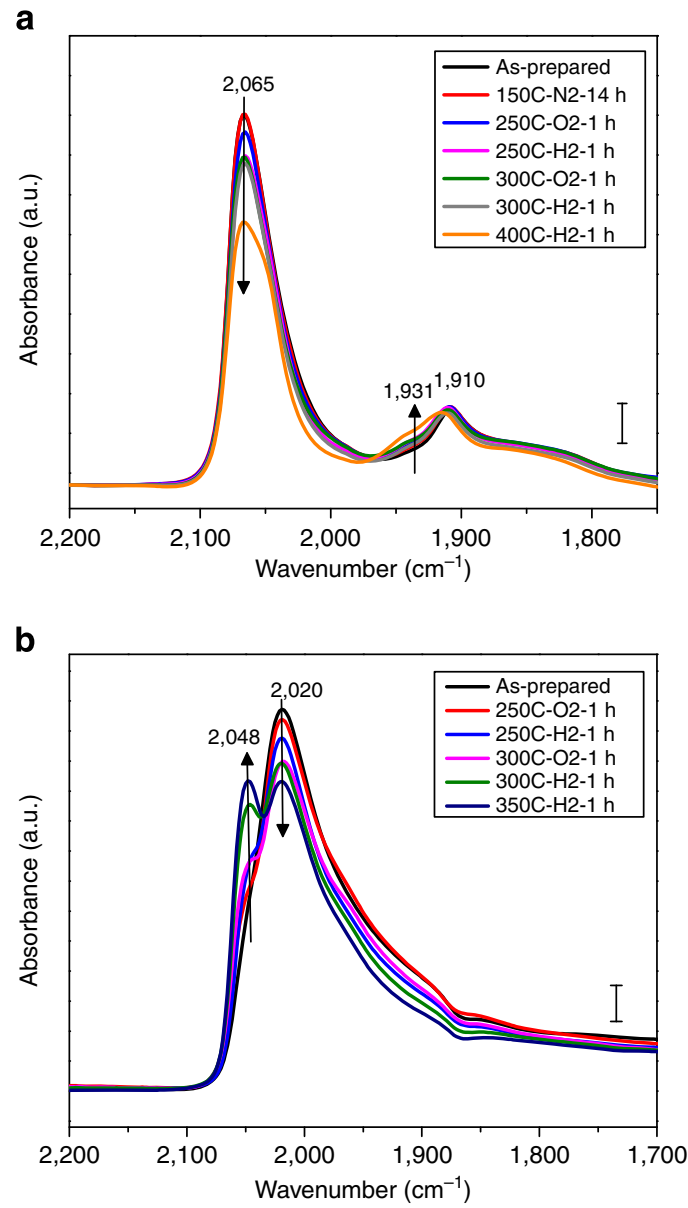

Figure 5 | In situ CO chemisorption FTIR studies of particle stability.

(a) The well-mixed $12 \mathrm{Pt10Pd}$ alloy nanoparticles treated at $150^{\circ} \mathrm{C}$ in nitrogen for $14 \mathrm{~h}(150 \mathrm{C}-\mathrm{N} 2-14 \mathrm{~h})$, then at 250,300 and $400^{\circ} \mathrm{C}$ in either $10 \% \mathrm{O}_{2}$ or $10 \% \mathrm{H}_{2}$ for $1 \mathrm{~h}$ ( $x \mathrm{C}-\mathrm{O} 2-1 \mathrm{~h}$ or $x \mathrm{C}-\mathrm{H} 2-1 \mathrm{~h}$ ). Scale bar $5 \%$.

(b) $1 \mathrm{Pt}$-core $35 \mathrm{Ru}$-rich-shell nanoparticles treated at 250,300 and $350{ }^{\circ} \mathrm{C}$ in either $10 \% \mathrm{O}_{2}$ or $10 \% \mathrm{H}_{2}$ for $1 \mathrm{~h}(x \mathrm{C}-\mathrm{O} 2-1 \mathrm{~h}$ or $x \mathrm{C}-\mathrm{H} 2-1 \mathrm{~h})$. Scale bar $3 \%$.

component. Finally, the structure of the bimetallic nanoparticles is controlled by the order in which the individual cycles are executed.

In situ FTIR measurements of $\mathrm{CO}$ chemisorption for the first time directly demonstrated this capability by mapping the atomic-scale evolution in the surface composition during bimetallic nanoparticle synthesis. During the growth of a Pt shell on a $\mathrm{Pd} / \mathrm{Al}_{2} \mathrm{O}_{3}$ catalyst, the gradual decrease of bridge-bonded $\mathrm{CO}$ on Pd $\left(1,917 \mathrm{~cm}^{-1}\right)$ and simultaneous increase of the linear $\mathrm{CO}$ on $\mathrm{Pt}$ provide direct evidence for the reduction in surface $\mathrm{Pd}$ concentration with increasing Pt ALD cycles (Fig. 3a). The completion of a continuous Pt shell on the Pd nanoparticle core occurred after $\sim 10 \mathrm{Pt}$ ALD cycles $(\sim 1.5 \mathrm{ML})$, as indicated by the disappearance of the bridge-bonded $\mathrm{CO}$ peak on Pd. Consequently, the Pt shell thickness on Pd nanoparticles can be precisely tuned by $\sim 0.15 \mathrm{ML}$ per cycle. Figure 3 demonstrates that the structure of the PdPt bimetallic nanoparticles can be controlled to be either core-shell or well-mixed alloy by tailoring the Pd and Pt ALD sequence, and this is corroborated by the HAADF-STEM measurements (Fig. 4). It is noteworthy that these synthesized ALD bimetallic nanoparticles are rather structurally and thermally stable at temperatures below $300^{\circ} \mathrm{C}$ in both oxidizing and reducing environments, which is very important for practical catalytic applications.
In conclusion, low temperature selective metal ALD is a versatile and powerful method for synthesizing supported, bimetallic nanoparticles. The self-limiting feature of ALD, combined with careful selection of the metal ALD co-reactants and deposition temperature, and the implementation of tailored ALD pulse sequences allow atomically precise control over the nanoparticle size, composition and structure. Having demonstrated this capability for all combinations of three metals on three metal oxide supports, it is likely that these methods are general and will apply to a broad range of other ALD metals and supports (Supplementary Fig. 14). In situ CO chemisorption FTIR is shown to be a powerful characterization tool to infer nanoparticle structure and composition as verified by STEM analysis. Although the economics of this methodology would need to be carefully considered before commercial application, ALD could complement other catalyst synthesis methods and offers a promising alternative synthetic route to supported bimetallic or multi-metallic catalysts.

\section{Methods}

Metal ALD. ALD was performed in a custom viscous flow stainless tube reactor system, using ultrahigh purity $\mathrm{N}_{2}$ (UHP, 99.999\%) carrier gas at a flow rate of $300 \mathrm{sccm}$ and a pressure of 1 Torr ${ }^{48}$. Pd ALD utilized Pd(hfac) $)_{2}$ (Sigma-Aldrich, $>97 \%$ ) and either formalin (Sigma-Aldrich) or $\mathrm{H}_{2}$ (refs 28,45). The $\mathrm{Pd}(\mathrm{hfac})_{2}$ was contained in a stainless steel bubbler heated to $60^{\circ} \mathrm{C}$. Pt ALD was conducted using $\mathrm{MeCpPtMe}_{3}$ (Sigma-Aldrich, 98\%) heated to $50{ }^{\circ} \mathrm{C}$ and either $\mathrm{O}_{3}$ or $\mathrm{O}_{2}$. Ru ALD was conducted via an $\mathrm{ABC}$ process using $\mathrm{Ru}(\mathrm{EtCp})_{2}$ (Sigma-Aldrich, 98\%) heated to $80^{\circ} \mathrm{C}, 99.999 \% \mathrm{O}_{2}$ and $99.99 \% \mathrm{H}_{2}$ at 150 or $200{ }^{\circ} \mathrm{C}$. The ALD timing sequences are expressed as $t_{1}-t_{2}-t_{3}-t_{4}$, corresponding to the metal precursor exposure time, the metal precursor purge time, the coreactant exposure time and the coreactant purge time, respectively, with all times in seconds (s). Similarly the ABC-type ALD timing sequences are expressed as $t_{1}-t_{2}-t_{3}-t_{4}-t_{5}-t_{6}$

In situ QCM measurements. We employed in situ QCM to investigate the metal ALD on both metal and oxide surfaces ${ }^{26,48,49}$. To examine the metal ALD on the $\mathrm{Al}_{2} \mathrm{O}_{3}, \mathrm{TiO}_{2}$ and $\mathrm{ZrO}_{2}$ surfaces, $\sim 10 \mathrm{~nm}$ of the oxide film was deposited on the QCM sensor by ALD before the metal ALD. The $\mathrm{Al}_{2} \mathrm{O}_{3}$ ALD used trimethylaluminum (TMA, Sigma-Aldrich, 97\%) and water (1-5-1-5); the $\mathrm{TiO}_{2}$ ALD used titanium tetraisopropoxide (TTIP, Sigma-Aldrich, 97\%) and water (2-5-2-5); and the $\mathrm{ZrO}_{2}$ ALD used tetrakis(dimethylamido)zirconium(IV) (TDMAZr, Sigma-Aldrich) and water (3-5-3-5). The TMA reservoir was held at room temperature, while the TTIP and TDMAZr bubblers were both heated to $80^{\circ} \mathrm{C}$. To examine metal ALD on the Ru, Pt and Pd surfaces, $\sim 5-10 \mathrm{~nm}$ of the primary metal was first deposited on the QCM sensor by ALD, after which the secondary metal ALD was performed. The timing sequences were (5-5-5-5) for the Pd ALD $\left(\mathrm{Pd}(\mathrm{hfac})_{2}+\mathrm{HCHO}\left(\right.\right.$ or $\left.\left.\mathrm{H}_{2}\right)\right),(2-5-5-5)$ for the Pt ALD $\left(\mathrm{MeCpPtMe}_{3}+\mathrm{O}_{2}\right)$ and (3-5-5-10-5-5) for the Ru ALD $\left(\mathrm{Ru}(\mathrm{EtCp})_{2}+\mathrm{O}_{2}+\mathrm{H}_{2}\right)$

In situ CO chemisorption FTIR. In situ CO chemisorption FTIR measurements were conducted to investigate the evolution of the surface composition after every ALD cycle of the secondary metal on the primary metal nanoparticles. The custom ALD-FTIR chamber consisted of a stainless steel cross with a pair of IR-transmissive $\mathrm{KBr}$ windows installed on opposite flanges with gate valves to protect the windows from the ALD coatings. The sample pellet was positioned in the center of the cross in the path of the IR beam and was prepared by pressing the spherical alumina powder (NanoDur, 99.5\%, Alfa Aesar) into a stainless steel grid (Fotofab, Chicago, IL). The FT-IR spectra were recorded using a Thermo Scientific Nicolet 6700 FT-IR spectrometer with an MCT detector. A typical FTIR spectrum was recorded at $4 \mathrm{~cm}^{-1}$ resolution using 256 scans. The FTIR chamber was heated to $150^{\circ} \mathrm{C}$ to minimize condensation during the ALD and maintained at 1 Torr pressure with a flow of $300 \mathrm{sccm}$ UHP $\mathrm{N}_{2}$.

The ALD nanoparticle sample was first calcined in $\sim 10 \% \mathrm{O}_{2}$ flow at $200{ }^{\circ} \mathrm{C}$ for $30 \mathrm{~min}$ then reduced in $\sim 10 \% \mathrm{H}_{2}$ at $150{ }^{\circ} \mathrm{C}$ for another $30 \mathrm{~min}$. An IR background spectrum was then collected under pure $\mathrm{N}_{2}$ flow. After closing the two IR-window gate valves, CO (Matheson, research purity, 99.998\%) was dosed for $60 \mathrm{~s}$ at a partial pressure of 0.3 Torr to saturate the ALD metal nanoparticle sample. Next, the ALD chamber was purged for $30 \mathrm{~s}$ to remove the gas phase CO. The two IR-window gate valves were then opened, and an IR spectrum was collected for the starting metal nanoparticles. To remove the chemisorbed $\mathrm{CO}$ and regenerate the clean metal surface, $\mathrm{O}_{2}$ was dosed for $120 \mathrm{~s}$ at a partial pressure of 0.2 Torr, followed by a $30 \mathrm{~s}$ $\mathrm{N}_{2}$ purge, and then $\mathrm{H}_{2}$ was dosed for $120 \mathrm{~s}$ at a partial pressure of 0.2 Torr. Next, ALD of the secondary metal was performed for a certain number of ALD cycles, and the procedure of $\mathrm{CO}$ chemisorption, FTIR, $\mathrm{O}_{2}$ burning and $\mathrm{H}_{2}$ reduction was repeated. In the case of $\mathrm{Pt}$ shell growth on the $\mathrm{Pd}$ nanoparticles, the $\mathrm{H}_{2}$ reduction step after CO burning was skipped since surface oxygen serves as the active site in 
Pt ALD. The timing sequences for the Pd, Pt and Ru ALD were (80-60-120-60), (70-60-120-30) and (120-60-60-60-60-60), respectively.

In situ $\mathrm{CO}$ chemisorption FTIR measurements were also used to investigate the thermal stability of ALD bimetallic nanoparticles. For the well-mixed 12Pt10Pd alloy sample, the thermal treatment was first carried out in $\mathrm{N}_{2}$ at $150^{\circ} \mathrm{C}$ for $14 \mathrm{~h}$, then in either $10 \% \mathrm{O}_{2}$ or $10 \% \mathrm{H}_{2}$ at 250,300 and $400{ }^{\circ} \mathrm{C}$ for $1 \mathrm{~h}$. The CO chemisorption spectra were collected at $150^{\circ} \mathrm{C}$ after each treatment step. In the case of $1 \mathrm{Pt}$-core $35 \mathrm{Ru}$-rich-shell sample, it was treated in either $10 \% \mathrm{O}_{2}$ or $10 \% \mathrm{H}_{2}$ at 250,300 and $350^{\circ} \mathrm{C}$ for $1 \mathrm{~h}$, and then the $\mathrm{CO}$ chemisorption spectra were collected at $200^{\circ} \mathrm{C}$ after each treatment step.

STEM. HAADF-STEM imaging was performed using a JEOL JEM-ARM200CF probe aberration-corrected cold-field emission STEM operating at $200 \mathrm{kV}$ with a point-resolution of less than $0.08 \mathrm{~nm}$. X-ray energy-dispersive spectroscopy (XEDS) experiments were performed using the same STEM instrument that is equipped with an Oxford Instrument's X-Max $80 \mathrm{~mm}^{2}$ silicon-drift detector. The line profile analysis was performed on multiple particles for each sample. The STEM instrument is located in the Research Resources Center at University of Illinois at Chicago.

\section{References}

1. Cortie, M. B. \& McDonagh, A. M. Synthesis and optical properties of hybrid and alloy plasmonic nanoparticles. Chem. Rev. 111, 3713-3735 (2011).

2. Ferrando, R., Jellinek, J. \& Johnston, R. L. Nanoalloys: From theory to applications of alloy clusters and nanoparticles. Chem. Rev. 108, 845-910 (2008).

3. Yu, W. T., Porosoff, M. D. \& Chen, J. G. G. Review of Pt-based bimetallic catalysis: From model surfaces to supported catalysts. Chem. Rev. 112, 5780-5817 (2012).

4. Alayoglu, S., Nilekar, A. U., Mavrikakis, M. \& Eichhorn, B. Ru-Pt core-shell nanoparticles for preferential oxidation of carbon monoxide in hydrogen. Nat. Mater. 7, 333-338 (2008).

5. Lim, B. et al. Pd-Pt bimetallic nanodendrites with high activity for oxygen reduction. Science 324, 1302-1305 (2009).

6. Greeley, J., Jaramillo, T. F., Bonde, J., Chorkendorff, I. B. \& Norskov, J. K. Computational high-throughput screening of electrocatalytic materials for hydrogen evolution. Nat. Mater. 5, 909-913 (2006).

7. Hutchings, G. J. \& Kiely, C. J. Strategies for the synthesis of supported gold palladium nanoparticles with controlled morphology and composition. Acc. Chem. Res. 46, 1759-1772 (2013).

8. Thomas, J. M., Johnson, B. F. G., Raja, R., Sankar, G. \& Midgley, P. A. High-performance nanocatalysts for single-step hydrogenations. Acc. Chem. Res. 36, 20-30 (2003).

9. $\mathrm{Mu}, \mathrm{R}$. T. et al. Synergetic effect of surface and subsurface Ni species at Pt-Ni bimetallic catalysts for CO oxidation. J. Am. Chem. Soc. 133, 1978-1986 (2011).

10. Enache, D. I. et al. Solvent-free oxidation of primary alcohols to aldehydes using Au-Pd/TiO2 catalysts. Science 311, 362-365 (2006).

11. Besenbacher, F. et al. Design of a surface alloy catalyst for steam reforming. Science 279, 1913-1915 (1998).

12. Huber, G. W., Shabaker, J. W. \& Dumesic, J. A. Raney Ni-Sn catalyst for $\mathrm{H}_{2}$ production from biomass-derived hydrocarbons. Science 300, 2075-2077 (2003).

13. Liu, Y. et al. Composition-controlled synthesis of bimetallic PdPt nanoparticles and their electro-oxidation of methanol. Chem. Mater. 23, 4199-4203 (2011).

14. Wang, J. X. et al. Oxygen reduction on well-defined core-shell nanocatalysts: Particle size, facet, and Pt shell thickness effects. J. Am. Chem. Soc. 131, 17298-17302 (2009).

15. Strasser, P. et al. Lattice-strain control of the activity in dealloyed core-shell fuel cell catalysts. Nat. Chem. 2, 454-460 (2010).

16. Maroun, F., Ozanam, F., Magnussen, O. M. \& Behm, R. J. The role of atomic ensembles in the reactivity of bimetallic electrocatalysts. Science 293, 1811-1814 (2001).

17. Wrobleski, J. T. \& Boudart, M. Preparation of solid catalysts: an appraisal. Catal. Today 15, 349-360 (1992).

18. Rebelli, J., Rodriguez, A. A., Ma, S. G., Williams, C. T. \& Monnier, J. R. Preparation and characterization of silica-supported, group IB-Pd bimetallic catalysts prepared by electroless deposition methods. Catal. Today 160, 170-178 (2011).

19. Puurunen, R. L. Surface chemistry of atomic layer deposition: A case study for the trimethylaluminum/water process. J. Appl. Phys. 97, 121301 (2005).

20. George, S. M. Atomic layer deposition: an overview. Chem. Rev. 110, 111-131 (2010).

21. Suntola, T. \& Hyvarinen, J. Atomic layer epitaxy. Ann. Rev. Mater. Sci. 15, 177-195 (1985).
22. Lim, B. S., Rahtu, A. \& Gordon, R. G. Atomic layer deposition of transition metals. Nat. Mater. 2, 749-754 (2003).

23. Pagan-Torres, Y. J. et al. Synthesis of highly ordered hydrothermally stable mesoporous niobia catalysts by atomic layer deposition. ACS Catal. 1, 1234-1245 (2011).

24. King, J. S. et al. Ultralow loading Pt nanocatalysts prepared by atomic layer deposition on carbon aerogels. Nano Lett. 8, 2405-2409 (2008).

25. Lu, J. L. et al. Coking- and sintering- resistant palladium catalysts achieved through atomic layer deposition. Science 335, 1205-1208 (2012).

26. Lu, J. L. \& Stair, P. C. Low-temperature ABC-type atomic layer deposition: synthesis of highly uniform ultrafine supported metal nanoparticles. Angew. Chem. Int. Ed. 49, 2547-2551 (2010).

27. Lu, J. L., Elam, J. W. \& Stair, P. C. Synthesis and stabilization of supported metal catalysts by atomic layer deposition. Acc. Chem. Res. 46, 1806-1815 (2013).

28. Lu, J. L. \& Stair, P. C. Nano/Subnanometer Pd nanoparticles on oxide supports synthesized by $\mathrm{AB}$-type and low-temperature $\mathrm{ABC}$-type atomic layer deposition: growth and morphology. Langmuir 26, 16486-16495 (2010).

29. Christensen, S. T. et al. Supported Ru-Pt bimetallic nanoparticle catalysts prepared by atomic layer deposition. Nano Lett. 10, 3047-3051 (2010).

30. Molenbroek, A. M., Haukka, S. \& Clausen, B. S. Alloying in $\mathrm{Cu} / \mathrm{Pd}$ nanoparticle catalysts. J. Phys. Chem. B 102, 10680-10689 (1998).

31. Weber, M. J., Mackus, A. J. M., Verheijen, M. A., van der Marel, C. \& Kessels, W. M. M. Supported core/shell bimetallic nanoparticles synthesis by atomic layer deposition. Chem. Mater. 24, 2973-2977 (2012).

32. Aaltonen, T. et al. Atomic layer deposition of noble metals: Exploration of the low limit of the deposition temperature. J. Mater. Res. 19, 3353-3358 (2004).

33. Kim, W. H., Park, S. J., Kim, D. Y. \& Kim, H. Atomic layer deposition of ruthenium and ruthenium-oxide thin films by using a $\operatorname{Ru}(\operatorname{EtCp})(2)$ precursor and oxygen gas. J. Korean Phys. Soc. 55, 32-37 (2009).

34. Feng, H., Libera, J. A., Stair, P. C., Miller, J. T. \& Elam, J. W. Subnanometer palladium particles synthesized by atomic layer deposition. ACS Catal. 1, 665-673 (2011).

35. Mott, D. et al. Synergistic activity of gold-platinum alloy nanoparticle catalysts. Catal. Today 122, 378-385 (2007).

36. Bradley, J. S., Via, G. H., Bonneviot, L. \& Hill, E. W. Infrared and EXAFS study of compositional effects in nanoscale colloidal palladium-copper alloys. Chem Mater. 8, 1895-1903 (1996).

37. Toshima, N. \& Yonezawa, T. Bimetallic nanoparticles-novel materials for chemical and physical applications. New. J. Chem. 22, 1179-1201 (1998).

38. Park, S., Wieckowski, A. \& Weaver, M. J. Electrochemical infrared characterization of CO domains on ruthenium-decorated platinum nanoparticles. J. Am. Chem. Soc. 125, 2282-2290 (2003).

39. Lear, T. et al. The application of infrared spectroscopy to probe the surface morphology of alumina-supported palladium catalysts. J. Chem. Phys. 123, 174706 (2005).

40. deMenorval, L. C., Chaqroune, A., Coq, B. \& Figueras, F. Characterization of mono- and bi-metallic platinum catalysts using CO FTIR spectroscopy-size effects and topological segregation. J. Chem. Soc. Faraday Trans. 93, 3715-3720 (1997).

41. Barcaro, G., Fortunelli, A., Polak, M. \& Rubinovich, L. Patchy multishell segregation in Pd-Pt alloy nanoparticles. Nano Lett. 11, 1766-1769 (2011).

42. Yanguas-Gil, A., Peterson, K. E. \& Elam, J. W. Controlled dopant distribution and higher doping efficiencies by surface-functionalized atomic layer deposition. Chem. Mater. 23, 4295-4297 (2011).

43. Christensen, S. T. \& Elam, J. W. Atomic layer deposition of Ir-Pt alloy films. Chem. Mater. 22, 2517-2525 (2010).

44. Senkevich, J. J. et al. Substrate-independent palladium atomic layer deposition. Chem. Vap. Deposition 9, 258-264 (2003).

45. Elam, J. W. et al. Atomic layer deposition of palladium films on $\mathrm{Al}_{2} \mathrm{O}_{3}$ surfaces. Thin Solid Films 515, 1664-1673 (2006).

46. Aaltonen, T., Rahtu, A., Ritala, M. \& Leskela, M. Reaction mechanism studies on atomic layer deposition of ruthenium and platinum. Electrochem. Solid St 6, C130-C133 (2003).

47. Kessels, W. M. M., Knoops, H. C. M., Dielissen, S. A. F., Mackus, A. J. M. \& van de Sanden, M. C. M. Surface reactions during atomic layer deposition of Pt derived from gas phase infrared spectroscopy. Appl. Phys. Lett. 95, 013114 (2009).

48. Elam, J. W., Groner, M. D. \& George, S. M. Viscous flow reactor with quartz crystal microbalance for thin film growth by atomic layer deposition. Rev. Sci. Instrum. 73, 2981-2987 (2002).

49. Lu, J. L. et al. Porous alumina protective coatings on palladium nanoparticles by self-poisoned atomic layer deposition. Chem. Mater. 24, 2047-2055 (2012).

\section{Acknowledgements}

J.L., Y.L., J.A.L. and J.W.E. were supported as part of the Institute for Atom-efficient Chemical Transformations (IACT), an Energy Frontier Research Center funded by the 
U.S. Department of Energy (DOE), Office of Science, Office of Basic Energy Science. The UIC RRC JEOL JEM-ARM200CF was partially funded by NSF MRI-R2 award no.DMR-0959470 ARRA.

\section{Authors contributions}

J.L. designed and conducted all the experiments. K.-B.L. performed aberration-corrected high-angle annular dark field-scanning transmission electron microscopy and $\mathrm{x}$-ray energy-dispersive spectroscopy. J.W.E. and J.A.L. developed and maintained the in situ FTIR-ALD system. J.L. prepared the manuscript. All the authors contributed to revising the manuscript.

\section{Additional information}

Supplementary Information accompanies this paper at http://www.nature.com/ naturecommunications

Competing financial interests: The authors declare no competing financial interests.

Reprints and permission information is available online at http://npg.nature.com/ reprintsandpermissions/

How to cite this article: Lu, J. et al. Toward atomically-precise synthesis of supported bimetallic nanoparticles using atomic layer deposition. Nat. Commun. 5:3264 doi: $10.1038 /$ ncomms4264 (2014). 